\title{
Interactions between $\beta$-Cyclodextrin and some Sodium Alkyl Sulfates and Sulfonates as Seen by Electrical Conductivity Measurements
}

\author{
Artur J.M. Valente," Carlos J.S. Dinis, Rui F.P. Pereira, \\ Ana C.F. Ribeiro, Victor M.M. Lobo \\ Department of Chemistry, University of Coimbra, 3004-535 Coimbra, Portugal
}

Received 13 May 2005

\begin{abstract}
A conductivity technique has been developed, being highly useful for studying the association behaviour of cyclodextrins (CDs) with surfactants. In this paper, the complexation of $\beta$-cyclodextrin with alkyl sulfonates and alkyl sulfates with different carbon chains (from 10 to 16) is analysed. The effect of the ionic head group in the most hydrophobic surfactant is also analysed. The association constants for 1:1 and 1:2 complexes are calculated on the basis of a second and a third degree equation; in the latter a real solution of a Cardin-Tartagliae formula is applied to solve the third degree equation.
\end{abstract}

Keywords: $\beta$-cyclodextrin, surfactants, conductivity, association constants.

\section{Introduction}

The beneficial modification of guest molecular properties after the formation of an inclusion compound leads to a large number of applications related to chemical synthesis and catalysis, pharmaceutical chemistry, and analytical chemistry [1].

Surfactants are particular guest compounds. The relevance of these studies is due to the fact that these systems can be used to mimic the effect of cyclodextrins on phospholipids, a major constituent of cell membranes [2]. Therefore, the properties of inclusion complexes formed between surfactants and CDs have received particular attention in the last two decades and different techniques [3-5] have been used.

\footnotetext{
* Corresponding author. E-mail address: avalente@ci.uc.pt
} 
Cyclodextrins are cyclic oligosaccharides [6] in the shape of truncated cones with hydrophilic external surfaces and relatively nonpolar cavities. The $\beta$-cyclodextrin is composed of seven glucose units, being the inner cavity diameter $0.78 \mathrm{~nm}$, and the total diameter $1.53 \mathrm{~nm}$. The height of these cyclodextrins is $0.79 \mathrm{~nm}$. The cavity is lined by the hydrogen atoms and the glycosidic oxygen bridges.

A significant property of CDs is their ability to include other organic or inorganic compounds into their cavities, both in the solid state and in solutions to form inclusion complexes. Such interactions result in an alteration of the physical properties of the solution, and these properties have been used in areas as divers as enzymatic synthesis [7], drug delivery [8], catalysis [9], and energy transfer studies [10]. The theoretical basis of such interactions has been analyzed [see, for example, ref. 11] to understand how cyclodextrins may affect the structures of compounds and their solutions [12].

There is a particular interest in the interaction of surfactants with cyclodextrins [13-15], both because the potential for modulating surfactant properties, and because the possible importance of mixed surfactant/cyclodextrin systems in commercial formulations [16-17].

In the present paper, the interactions between $\beta$-cyclodextrin and sodium alkyl sulfonates are analysed by electrical conductivity measurements. The effect of the chain size (from $\mathrm{C} 12$ to $\mathrm{C} 16$ ) in the sodium alkyl sulfonates in $\beta$-cyclodextrin solutions is analysed. With an appropriate approach, the association constants for 1:1 and 1:2 (surfactant: cyclodextrin) complexation are calculated.

\section{Experimental}

$\beta$-CD was purchased from Aldrich with a water content of $13.1 \%$, as determined from thermal analysis. Sodium decyl 1-sulfate (DSA), sodium dodecyl benzene sulfonate (SDBS), sodium hexadecyl 1-sulfate (SHS) and sodium hexadecyl 1sulfonate (SHSo) were obtained from Aldrich and they were used without further purification.

Aqueous solutions were prepared by using Millipore water $\left(\kappa=(0.7-0.9) \times 10^{-4} \mathrm{~S}\right.$ $\left.\mathrm{m}^{-1}\right)$. All solutions were freshly prepared just before each experiment.

Solution electrical resistances were measured with a Wayne-Kerr model 4265 Automatic LCR meter at $1 \mathrm{kHz}$. A Shedlovsky-type conductance cell, with a cell constant of around $0.8465 \mathrm{~cm}^{-1}$ was used [18]. Measurements were taken at 25.00 $\pm 0.01{ }^{\circ} \mathrm{C}$ in a Grant thermostat bath. Solutions were always used within 12 hours after preparation. In a typical experiment, a surfactant solution was placed in the conductivity cell; then, aliquots of the $\beta-\mathrm{CD}$ solution (the solvent used is the same surfactant solution placed in the conductivity cell) were added in a stepwise manner using a micropipette. The conductance of the solution was measured after each addition.

\section{Experimental Results}

Figs. 1 and 2 show the effect upon the molar conductances of pre-micellar sodium decyl 1-sulfate $\left(\mathrm{cmc}=3.26 \times 10^{-2} \mathrm{M}\right)$ [19] and sodium dodecyl benzene 1sulfonate $\left(\mathrm{cmc}=1.6 \mathrm{mM}\left(23^{\circ} \mathrm{C}\right)\right)[19]$ solutions of adding $\beta$-cyclodextrin. The molar conductance decreases sharply as $\beta$-CD was added because the anionic 
surfactants complexed by $\beta-\mathrm{CD}$ are less effective as charge carrier. In this procedure we assume that sodium ions are not complexed in any extent [20]. It is also possible to find that the alteration on the surfactant molar conductivity, with the increasing of $\beta-\mathrm{CD}$ concentration, is markedly higher with $\mathrm{C} 12$ sulfonate than with $\mathrm{C} 10$ sulfate derivative.

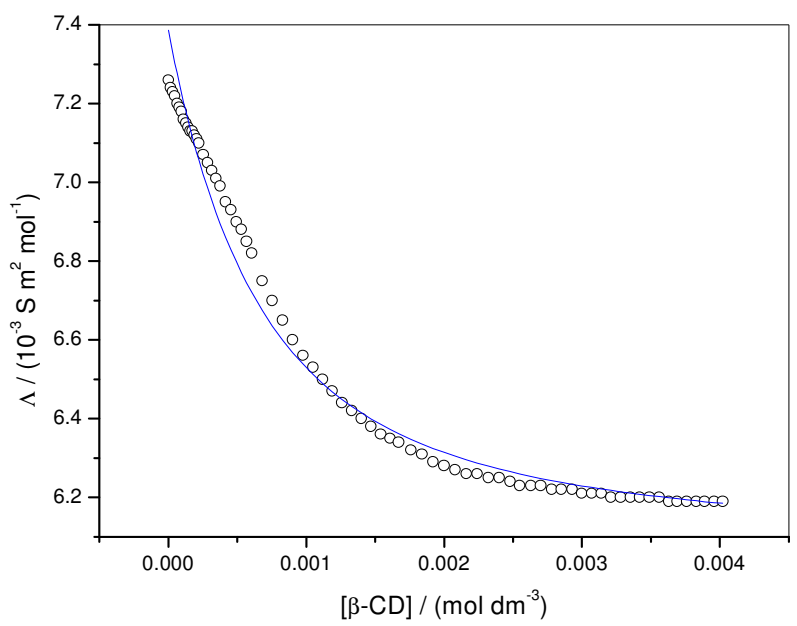

Figure 1. Molar conductivity of $1.007 \mathrm{mM}$ sodium decyl 1-sulfate with added $\beta$ cyclodextrin. Solid line represents molar conductivities predicted by eqs. (1-9) using the parameters shown in Table 1 (see following section for details).

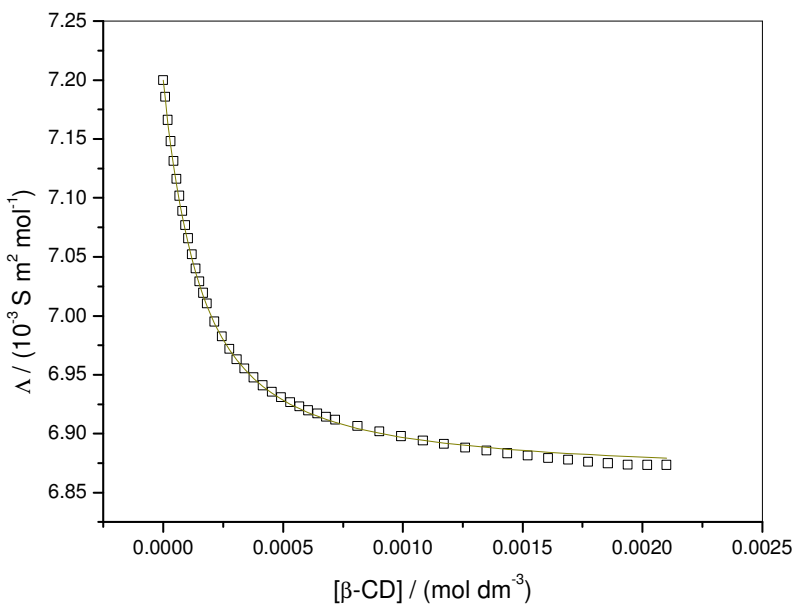

Figure 2. Molar conductivity of $0.110 \mathrm{mM}$ sodium dodecyl benzene 1-sulfonate with added $\beta$-cyclodextrin. Solid line represents molar conductivities predicted by eqs. (1-9) using the parameters shown in Table 1 (see following section for details). 


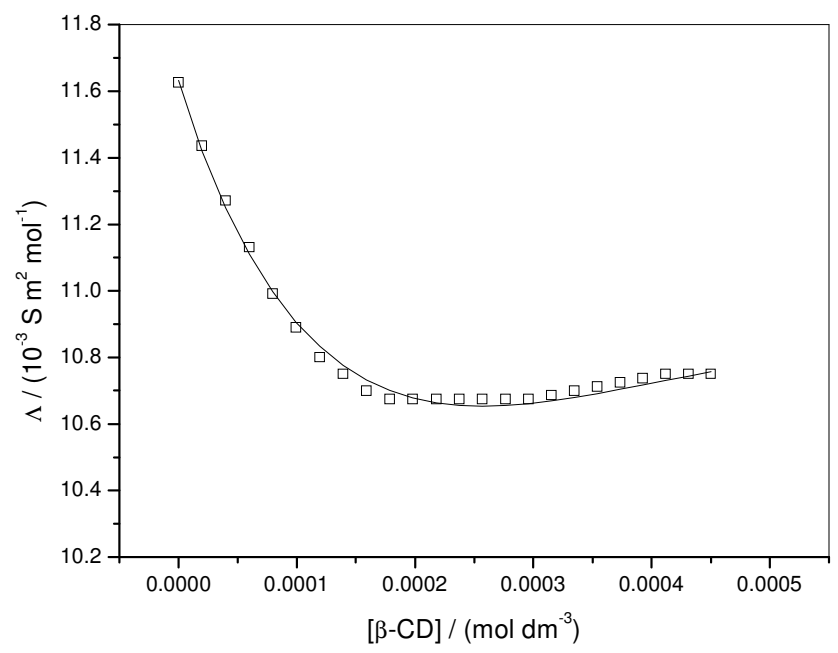

Figure 3. Molar conductivity of $0.0958 \mathrm{mM}$ sodium hexadecyl sulfate with added $\beta$ cyclodextrin. Solid line represents molar conductivities predicted by eqs. (1-9) using the parameters shown in Table 1 (see following section for details).

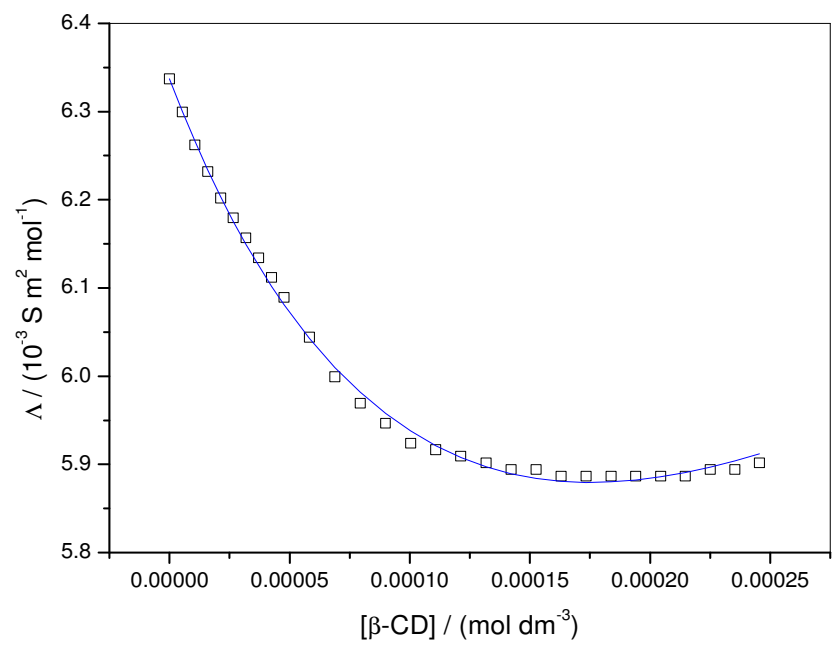

Figure 4. Molar conductivity of $0.1065 \mathrm{mM}$ sodium hexadecyl sulfonate with added $\beta$ cyclodextrin. Solid line represents molar conductivities predicted by Eqs. (1-9) using the parameters shown in Table 1 (see following section for details).

Figs. 3 and 4 show the effect of $\beta-C D$ on the molar conductivity of sodium hexadecyl sulfate $\left(\mathrm{cmc}=5.8 \times 10^{-4} \mathrm{M}, \mathrm{T}=40{ }^{\circ} \mathrm{C}[19]\right)$ and sulfonate $(\mathrm{cmc}=$ $\left.7.0 \times 10^{-4} \mathrm{M}, \mathrm{T}=50^{\circ} \mathrm{C}[19]\right)$, respectively. In these figures, the effect of the anionic head group on a C16 structure surfactant is analysed. The experiments were carried out in the absence of micelles.

The effect of $\beta$-CD addition on the conductance curves of DSA and SDBS shows a two different linear section, the intersection of which indicates 1.1:1 and 1.2:1 (cyclodextrin: surfactant) stoichiometric species. This procedure can be done 
assuming a very high equilibrium constant to complex formation (see, e.g., eq. 1). These stoichiometric values may suggest that mainly 1:1 complexes are formed. This is in close agreement with those data reported in literature to surfactants with the same carbon chain length $[13,21]$. However, the analysis of the systems with hexadecyl derivatives is rather complicated once no linear sections are clearly found; furthermore, it is possible to observe that a slightly increase in the molar conductivity occurs at higher $\beta-C D$ concentrations; such increase can be modelled using a 2:1 complexation, which is also in agreement with data reported in the literature [see, for example, ref. 21].

\section{Modelling approach}

From the above discussion, the interaction of the surfactant (S) and CD may lead to $1: 1$ and/or $1: 2$ complexations. On the assumption that a $1: 1$ complex (CD-S) between $\beta$-cyclodextrin (CD) and surfactant (S) is formed (cf. eq. (1) below), the stability of the inclusion complex can be described in terms of an association constant, $\mathrm{K}_{1}$, as defined in eq. (2):

$$
\begin{gathered}
\mathrm{CD}+\mathrm{S} \rightleftharpoons \mathrm{CD}-\mathrm{S} \\
\mathrm{K}_{1}=[\mathrm{CD}-\mathrm{S}] /([\mathrm{CD}][\mathrm{S}])
\end{gathered}
$$

In the circumstances where a $2: 1(\mathrm{CD}: \mathrm{S})$ association takes place, the following equilibrium should be considered

$$
\mathrm{CD}-\mathrm{S}+\mathrm{S} \rightleftharpoons \mathrm{CD}_{2}-\mathrm{S}
$$

and, consequently the association constant, $\mathrm{K}_{2}$, is defined as

$$
\mathrm{K}_{2}=\left[\mathrm{CD}_{2}-\mathrm{S}\right] /([\mathrm{CD}][\mathrm{S}])
$$

According to the law of conservation of mass

$$
[\mathrm{S}]_{\text {free }}=[\mathrm{S}]_{\text {total }}-[\mathrm{CD}-\mathrm{S}]-\left[\mathrm{CD}_{2}-\mathrm{S}\right]
$$

and

$$
[\mathrm{CD}]_{\text {free }}=[\mathrm{CD}]_{\text {total }}-[\mathrm{CD}-\mathrm{S}]-2\left[\mathrm{CD}_{2}-\mathrm{S}\right]
$$

Considering the $\mathrm{CD}$ concentration range where the free monomer surfactant and the free $\beta-C D$ are in equilibrium with the complexes, the observed specific conductance, $\kappa$, can be expressed as

$$
\kappa=\kappa_{\mathrm{S}}+\kappa_{\mathrm{CD}-\mathrm{S}}+\kappa_{\mathrm{CD}_{2}-\mathrm{S}}
$$

where $\kappa_{\mathrm{S}}, \kappa_{\mathrm{CD}-\mathrm{S}}$ and $\kappa_{\mathrm{CD}_{2} \text {-S }}$ are surfactant and the complexes $(1: 1$ and $2: 1)$ specific conductances. 
Taking into account the definition of molar conductivity, and from eqs. (1-6), eq. (7) can be re-written as

$$
\Lambda=\frac{\Lambda_{S}+\Lambda_{C D-S} K_{1}[C D]+\Lambda_{C D 2-S} K_{1} K_{2}[C D]^{2}}{1+K_{1}[C D]+K_{1} K_{2}[C D]^{2}}
$$

where $\Lambda$ is the observed molar conductivity. The free cyclodextrin concentration $[\mathrm{CD}]$ is given by

$$
[C D]^{3}+\left(\frac{1}{K_{2}}-[C D]_{t}+2[S]_{t}\right)[C D]^{2}+\left(\frac{1}{K_{1} K_{2}}+\frac{[S]_{t}}{K_{2}}-\frac{[C D]_{t}}{K_{2}}\right)[C D]-\frac{[C D]_{t}}{K_{1} K_{2}}=0
$$

The free cyclodextrins concentration can be estimated through an analytical solution of the real solution of a third-degree equation

$$
f(x)=x^{3}+a x^{2}+b x+c
$$

using a so-called Cardin-Tartaglia formulae

$$
x=r-(1 / 3) a-(q / r)
$$

where

$$
q=\frac{1}{3} b-\frac{1}{9} a^{2}
$$

and

$$
r=\sqrt[3]{\frac{1}{6} a b-\frac{1}{2} c-\frac{1}{27} a^{3}+\sqrt{\frac{1}{27} b^{3}-\frac{1}{6} a b c+\frac{1}{4} c^{2}+\frac{1}{27} a^{3} c-\frac{1}{108} a^{2} b^{2}}}
$$

Once the value of [CD] has been obtained (Eq. 9), the values of the other parameters involved were calculated using the GNUPLOT software. The obtained results for association constants, $\mathrm{K}$, correspond to those where the sum of squares of the residuals between calculated and observed values of the molar conductivity is minimized. The calculated association constants and other fitting parameters are given in Table 1.

In the less hydrophobic surfactants (DSA and SDBS), an increase of the carbon chain length (from $\mathrm{C} 10$ to $\mathrm{C} 12$ ) is followed by an increase of $\mathrm{K}_{1}$ in a factor of 4 . These results can be compared to those reported in literature to DSA/ $\alpha-C D$, $\mathrm{K}_{1}=2020 \mathrm{M}^{-1}$ [13] and to SDBS/ $\alpha-\mathrm{CD}, \mathrm{K}_{1}=5730 \mathrm{M}^{-1}$ [13]. These results show that, increasing the hydrophobicity of the surfactant, the solution becomes more entropic, and the presence of a hydrophobic cavity of cyclodextrin, which will be able to reduce such entropy, is quite favourable increasing $\mathrm{K}$. Comparing the values of $\alpha$ - and $\beta$-CD to DSA, it is possible to observe that $K$ is higher in the 
system where surfactant fits well the cyclodextrin cavity; however, when the surfactant carbon chain length increases, such effect becomes less important and can be even neglected once the entropy of the mixture becomes the main parameter influencing complexation and, consequently, association constants drastically increase. In fact, $\mathrm{K}_{1}$ to SDBS in $\alpha$ - and $\beta$-CD are approximately the same. This is consistent with the results reported elsewhere [5].

Table 1. Association constants for the inclusion complexes $\mathrm{S}: \mathrm{CD}$ at $25^{\circ} \mathrm{C}$.

\begin{tabular}{cccccccc}
\hline S & $\begin{array}{c}{[\mathrm{S}]_{\text {total }} /} \\
\mathrm{mM}\end{array}$ & $\begin{array}{c}\Lambda_{\mathrm{S}} /\left(\mathrm{S} \mathrm{m}^{2}\right. \\
\left.\mathrm{mol}^{-1}\right)\end{array}$ & $\begin{array}{c}\Lambda_{\mathrm{CD}-\mathrm{S}} /\left(\mathrm{S} \mathrm{m}^{2}\right. \\
\left.\mathrm{mol}^{-1}\right)\end{array}$ & $\begin{array}{c}\Lambda_{\mathrm{CD}_{2}-\mathrm{S}} /(\mathrm{S} \\
\left.\mathrm{m}^{2} \mathrm{~mol}^{-1}\right)\end{array}$ & $K_{1} / \mathrm{M}^{-1}$ & $K_{2} / \mathrm{M}^{-1}$ & Res* \\
\hline DSA & 1.01 & 0.00379 & 0.00513 & & 1375 & & $1.72 \times 10^{-7}$ \\
SDBS & 0.110 & 0.00720 & 0.00635 & & 5960 & & $5.56 \times 10^{-10}$ \\
SHS & 0.0958 & 0.01163 & 0.00932 & 0.01129 & 9700 & 6760 & $1.15 \times 10^{-8}$ \\
SHSo & 0.106 & 0.00634 & 0.00467 & 0.00685 & 8090 & 6600 & $1.47 \times 10^{-9}$ \\
& & & & & &
\end{tabular}

The effect of the ionic head group in the C16 surfactant is also analysed. The fitting of experimental data to eqs. (1-9) shows that $\mathrm{K}_{1}>\mathrm{K}_{2}$, which indicates that the formation of the 1:1 stoichiometric complex predominates rather than the 2:1. It is also found that the global association constants $\left(\mathrm{K}=\mathrm{K}_{1} \cdot \mathrm{K}_{2}\right)$ are approximately the same to sulfate and sulfonate hexadecyl surfactants, $6.6 \times 10^{7} \mathrm{M}^{-2}$ and $5.3 \times 10^{7}$ $\mathrm{M}^{-2}$, respectively. These results show that the applied model can be used to calculate the association constants even for very hydrophobic surfactants.

\section{Acknowledgments}

We thank Professors Hugh Burrows (Univ. Coimbra) and Rui Ralha (Univ. Minho) for valuable comments, and the POCTI, FCT and FEDER for financial support.

\section{References}

1. S. Li, W.C. Purdy, Chem. Rev. 92 (1992) 1457.

2. V.C. Reinsborough, Langmuir 11 (1995) 2476.

3. E. Junquera, L. Pena, E. Aicart, Langmuir 11 (1995) 4685.

4. N.M. Gorman, J. Laynez, A. Schon, J. Suurkusk, I. Wadso, J. Biochem. Biophys. Methods 10 (1984) 187.

5. A.J.M. Valente, M. Nilsson, O. Söderman, J. Colloid Interf. Sci. 281 (2005) 218.

6. K. Uekama, F. Hirayama, T. Irie, Chem. Rev. 98 (1998) 2045. 
7. T. Zelinski, A. Liese, C. Wandrey, M.-R. Kula, Tetrahedron Asymmetry 10 (1999) 1681.

8. M. Guyot, F. Fawaz, J. Bildet, F. Bonini, A.M. Laguen, Int. J. Pharm. 123 (1995) 53.

9. M. Nstoli, V. Pagliero, F. Trotta, E. Drioli, J. Mol. Catal. A Chem. 121 (1997) 179.

10. S. Lis, M. Elbanowski, B. Makawska, Z. Hnatejko, J. Photochem. Photobiol. A Chem. 150 (2002) 233.

11. S. Letellier, B. Maupas, J.P. Gramond, F. Guyon, P. Garei, Anal. Chim. Acta 315 (1995) 357.

12. B.S. Jursic, Z. Zdravkovski, A.D. French, J. Mol. Struct. THEOCHEM 366 (1996) 113.

13. I. Satake, T. Ikenoue, T. Takeshita, K. Hayakawa, T. Maeda, Bull. Chem. Soc. Jpn. 58 (1985) 2746.

14. I. Satake, S. Yoshida, K. Hayakawa, T. Maeda, Y. Kusumoto, Bull. Chem. Soc. Jpn. 59 (1986) 3991.

15. R. Palepu, J.E. Richardson, V.C. Reinsborough, Langmuir 5 (1989) 218.

16. D.J. Jobe, V.C. Reinsborough, S.C. Wetmore, Langmuir 11 (1995) 2476.

17. L. Karlson, C. Malmborg, K. Thuresson, O. Söderman, Colloids Surf. A Physicochem. Eng. Aspects 228 (2003) 171.

18. A.C.F. Ribeiro, A.J.M. Valente, E.F.G. Azevedo, A.M. Amado, A.M. Amorim da Costa, M.L. Ramos, H.D. Burrows, J. Mol. Struct. 703 (2004) 93.

19. P. Mukerjee, K.J. Mysels. In "Critical Micelle Concentration of Aqueous Surfactant Systems", National Bureau of Standards, Washington, D.C., 1971.

20. R. Palepu, V.C. Reinsborough, Can J. Chem. 66 (1988) 325.

21. A.A. Rafati, A. Bagheri, H. Iloukani, M. Zarinehzad, J. Molec. Liquids 116 (2005) 37. 